\title{
An Investigation into Students' Agentic Engagement in Online English Listening Learning
}

\author{
Yanxiu Dong \\ School of English Language, Culture and Literature, Beijing International Studies University, China \\ Suli Liu* \\ School of English Language, Culture and Literature, Beijing International Studies University, China
}

\begin{abstract}
This paper provides a comprehensive review on the current situation of non-English major students' agentic engagement in online English listening course. The paper aims to investigate students' low motivation in doing their online listening homework. Paper questionnaires and SPSS 22.0 were used to analyze the results. 46 freshmen and $\mathbf{4 3}$ sophomores of non-English majors participated in this research. It has been found that the agentic engagement of non-English majors is low and freshmen's average agentic engagement is higher than sophomores'. Besides, it doesn't have significant correlations with students' scores in online weekly tasks. The research findings indicate the importance of raising teachers' awareness of student agentic engagement, and a more effective e-learning platform is required. At last, with the results of this investigation, the current study provides some suggestions for future English listening course design.
\end{abstract}

Index Terms — engagement, agentic academic engagement, e-learning

\section{INTRODUCTION}

The higher education quality assessment paradigm shifts from the focus on resource input to the focus on college student engagement which is a hot issue of common concern in the higher education fields. The investigation of college student engagement has become a new trend in the field of higher education quality assessment. Besides, rapid developments in communication technology enable higher education to have various teaching models, such as online learning.

Influenced by the fact the network communication is taken as the main cognitive tool, teachers and students' status compared with their status in the traditional teaching mode change a lot. Students become the main body of their learning process. Still, teachers play an important role in helping students learn English successfully. Students, who play a more important role in their own learning process, should be involved in learning activity actively. That is to say, student's engagement in their English learning is crucial.

As for the target foreign language university in this study, English listening teacher tries to teaching listening course totally through an interactive English learning platform for one semester. This platform offers a series of listening tasks for one semester and asks students to finish them each week. By using this English learning platform, there are no face to face teaching producers. But teacher-student interaction can be done on this learning platform. Then, all the assignments and courses are passed through the internet. Therefore, teachers upload listening tasks every week, and students have to finish it in one week. Then, teachers will grade students' homework on the platform, and give them feedback in time.

Usually one teacher is in charge of seven classes, which means about 160 students in total. However, students usually forget to do their online homework even if their teachers remind them every week. Students' negative attitude toward online English listening can be classified as demotivation, which is an important issue in the field of second language learning motivation. It seems that student's engagement is not enough. Then, whether students' low motivation in online English listening learning has something related with student's agentic academic engagement in English need to be further studied.

\section{LITERATURE REVIEW}

\section{A. Engagement}

Engagement in education field also called student engagement or academic engagement is defined as students' active

\footnotetext{
* corresponding author, address: School of English Language, Culture and Literature, Beijing International Studies University, China; zip code:100024; e-mail address: liusuli@ bisu.edu.cn 
involvement in a learning activity (Christenson, Reschly, \& Wylie, 2012). It was first raised by Astin (1999) who used "student involvement" to express similar meaning. It's a multidimensional construct which consists of three subsystems__ behavioral, emotional, and cognitive (Christenson et al., 2012). Behavioral engagement refers to how involved the student is which concerning student's attention, effort, and persistence in learning activity; emotional engagement is defined as the presence of positive emotions during task involvement and the absence of negative emotions; and cognitive engagement refers to the degree of students attempts to learn strategically, which means students employ sophisticated rather than superficial learning strategies, such as students use elaboration rather than memorization. (Reeve, 2013). These three aspects are intercorrelated and mutually supportive (Fredricks, Blumenfeld, $\&$ Paris, 2004). Most of engagement studies are based on these three dimensions.

Researches concerning engagement mainly focus on two aspects: measurement of engagement and factors that influence engagement. As for the measurement of engagement, researchers designed many engagement scales for different research objects. In terms of college student engagement study, there are some mature scales and measurement models, such as National Survey of Student Engagement (NSSE). At the beginning of the $20^{\text {th }}$ century, NSSE as an important investigation instrument of higher education management in the United States, provides new perspective for higher education assessment. Many universities in America do teaching management according to the results of NSSE, which promotes the development of higher education. With the help of NSSE team in America, Chinese scholars developed NSSE-CHINA in 2009. By doing experiment, Chinese researchers have proved the reliability of NSSE-CHINA, and widely used this scale to investigate student engagement in China (Yang \& Han, 2014).

Factors that influence student engagement also attract scholars' attention. Related researches focus can be classified into students' internal factors and external factors. Internal factors include self-efficacy, goal orientation, fear of failure and so on (Caraway, Tucker, Reinke, \& Hall, 2003). External factors mainly include teacher's and peer's attitudes and action (Beachboard, Beachboard, Li, \& Adkison, 2011; Fredricks et al., 2004), school environment (Yang \& Han, 2014), and family background (Han, 2014). In general, current researches concerning factors that influence student engagement have been carried out from the perspective of psychology and sociology. Finding factors that can predict student engagement so as to take appropriate intervention is the main purpose of engagement studies.

In recent years, scholars have gradually begun to pay more attention to students' academic engagement in specific subject areas, such as foreign language engagement. Foreign language academic engagement refers to the learner's degree of effort or investment which act on language knowledge, language skills and related knowledge in foreign language learning process (Guo \& Liu, 2016). By doing empirical research concerning college students' foreign language academic engagement, Guo and Liu (2016) found that Chinese college students put a lot of effort into behavioral engagement, but less effort into emotional and cognitive engagement. Their findings largely reflected the imbalance of Chinese college students' engagement. In addition, researchers also have noticed factors that may influence student's foreign language academic engagement. For example, Su (2019) found that motivation has positive effects on student's foreign language academic engagement and anxiety has a negative effect on student's foreign language academic engagement.

\section{B. Agentic Engagement}

With the deepening of engagement study, Reeve and Tseng (2011) put forward the fourth dimension of engagement_agentic engagement. They defined it as "students' constructive contribution into the flow of the instruction they receive". Reeve and Tseng (2011) admitted that students become behaviorally, emotionally, and cognitively in teaching activities and those indicators could predict achievement. They argued that students do more than this. Students also attempt to create a more motivationally supportive learning environment for themselves (Bandura, 2018). What students do (display engagement) affects and transforms what teachers do (provide instruction) and vice versa (Reeve \& Tseng, 2011). Therefore, Reeve and Tseng (2011) pointed out that agentic engagement can be viewed as an ongoing series of dialectical transactions between student and teacher. They made the following figure 1 to show the relationship among the four related aspects of student engagement in the instructional flow.

The six curved lines with double-sided arrows show the positive intercorrelations among the four aspects of engagement. The curved line with single arrow at the bottom of this figure shows the unique contribution of agentic engagement to constructive changes in the learning environment. It can be viewed as the students' attempt to join forces with the teacher to create a more supportive learning environment, which is qualitatively distinct from the other three aspects of engagement as they are intentional, proactive, and teacher-collaborative ways of engaging in learning activities (Reeve \& Tseng, 2011). This unique contribution together with four aspects of engagement explains student's positive outcomes. 


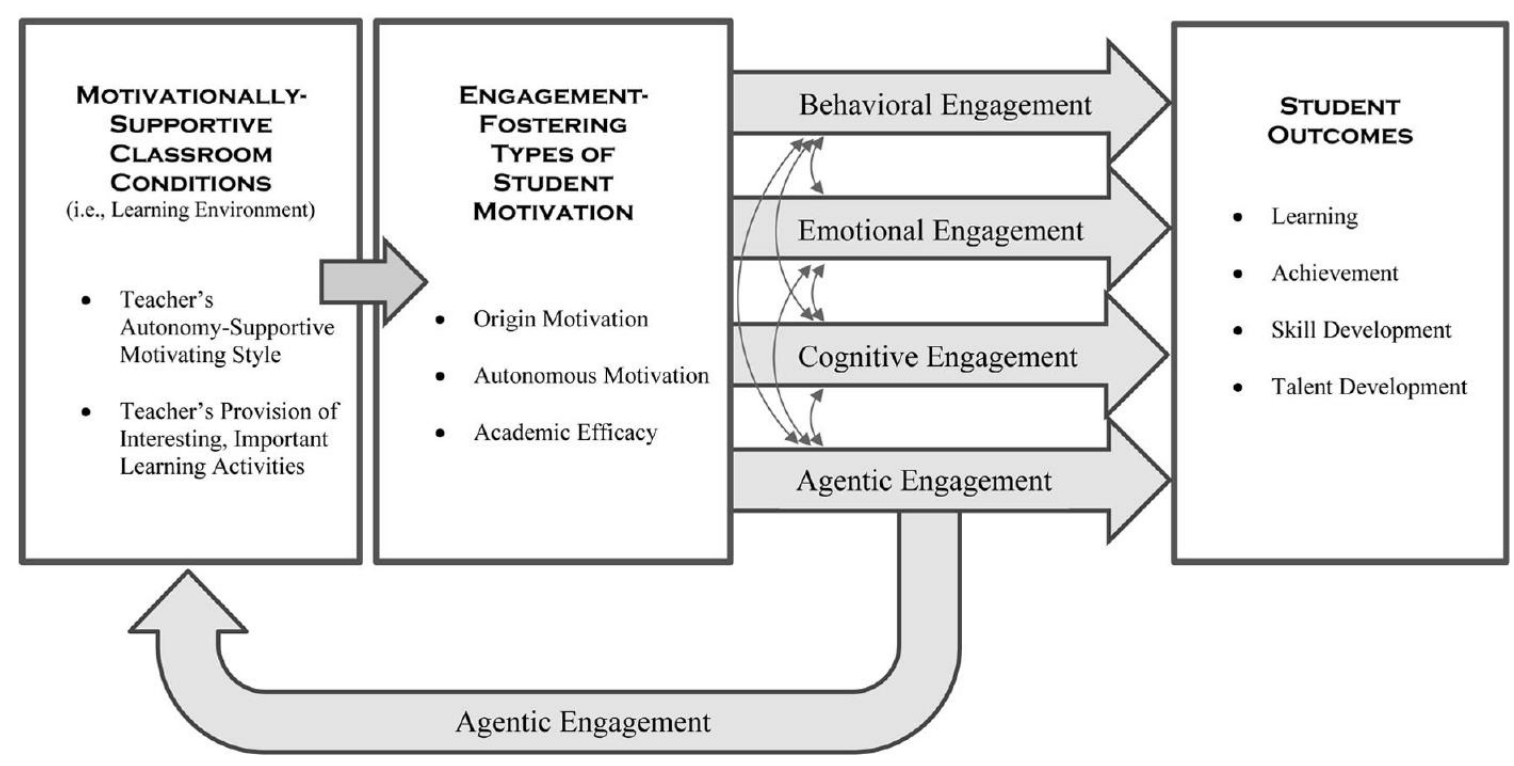

Figure 1 Four Related Aspects Of Student Engagement (Reeve \& Tseng, 2011)

Compared with large numbers of engagement researches concerning other three aspects, agentic researches are limited. Similarly, researches in regard to agentic engagement mainly consist of the measurement of agentic engagement and factors that influence agentic engagement. Given the importance of measuring student' agentic engagement, an effective questionnaire for this dimension is required. Reeve and Tseng (2011) initially made effort in this direction and put forward Agentic Engagement Scale (AES), which is a short self-report tool made up of five items. A few years afterwards, Reeve (2013) proposed an adapted version of AES, and pointed out that future research will be better positioned to improve the assessment of the construct. Based on Reeve's suggestion, Mameli and Passini (2019) proposed an enlarged version of student Agentic Engagement Scale. Their findings showed that both the original and the enlarged versions of the scale show significant and positive associations with other three engagement dimensions. Considering AES may not apply to Chinese English learners, Guo (2018) put forward College Student Agentic Engagement in English Scale for Chinese college students, which provided researchers with a new perspective of foreign language engagement studies.

With regard to factors that influence student agentic engagement, researchers have noticed the influence of curriculum (Fitzpatrick, O'Grady, \& O'Reilly, 2018), scaffolding (Fletcher, 2016), test anxiety (Maralani, Shalbaf, \& Lavasani, 2018), bi-directional dialogue and respect (Pineda-Báez, Hennig Manzuoli, \& Vargas Sánchez, 2019). Researchers argued that agentic engagement deserved special attention (Manzuoli, Pineda-Báez, \& Sánchez, 2019). However, agentic engagement studies in China are rare, which stimulate researchers to study the dimension in more depth.

\section{Agentic Engagement and E-learning}

E-learning also called online learning through networked computer has been available since early 1990s (Hockly, 2015). It has been widely applied as autonomous learning course in higher education in recent years, because of its "economic imperative" and convenience. At the very beginning, researchers mainly focused on that topic that to what extent that online course is better than face-to-face course, which was called "wrong research question" by Blake (2009). Shortly afterwards, how to make online learning courses more effective becomes the main topic (Hockly, 2015).

Engagement as an important index to measure students' effective learning is gradually connected with e-learning studies. Some researchers have suggested that technology have positive effects on student engagement (Henrie, Halverson, \& Graham, 2015). Accordingly, Restauri, King, and Nelson (2001) argued that improperly functioning technology can hinder learning and engagement. Other factors that may influence student engagement, such as teacher's and peer's feedback (Wijekumar, Ferguson, \& Wagoner, 2006), online course design (Pollock \& Wilson, 2002), have been noticed in recent studies. All in all, recent studies usually take "student engagement" as a whole, rather than focusing on one of the four engagement dimensions.

Although various e-learning platforms enable learners to counteract the physical limitation of the offline learning, many online programs face a serious dropout problem. One of the main reasons for dropout is a lack of interaction between learners and instructors which lead to feelings of isolation among learners (Wang, Guo, He, \& Wu, 2019). Then, students do online learning passively without giving any feedback to their instructors. Furthermore, additional motivation, organization, and self-discipline are important for students to be successful in their online learning (Jacob \& Radhai, 2016). As it is mentioned before, agentic engagement is "students' constructive contribution into the flow of the instruction they receive" (Reeve \& Tseng, 2011), which stresses students' actively create a more supportive learning 
environment for themselves. Thus, student's agentic engagement could be a crucial index that reflects student's online learning process.

Researches concerning student agentic engagement in online learning are rare, although achievements concerning agentic engagement are significant. However, these research findings may not be applicable for the current situation of student agentic engagement in online learning. Although nowadays online learning platform provide students with the nearly same chance to interact with teachers and classmates as another form of teaching activities in classroom, they are different learning environment for students. Besides, few researchers combine students' agentic academic engagement with students' autonomous learning ability.

Given these previous findings, this study did an empirical research to find the current situation of students' agentic engagement in online language learning. In addition, this study tried to investigate the relationship between students' agentic engagement and their online test score. By doing this, the current study aimed to provide teachers some suggestions for the usage of e-learning course, so as to promote students' autonomous e-learning.

\section{RESEARCH DESIGN}

\section{A. Research Questions}

This study mainly investigates the following questions via a questionnaire and interview.

1. What's the current situation of students' agentic engagement in online learning?

2. Does student's agentic engagement corelate with their online test scores?

\section{B. Participants}

The participants of this study come from a foreign language university in China. Four classes of different majors participated in this research. They are 46 freshmen and 43 sophomores of non-English majors. The total number of participants is 89 .

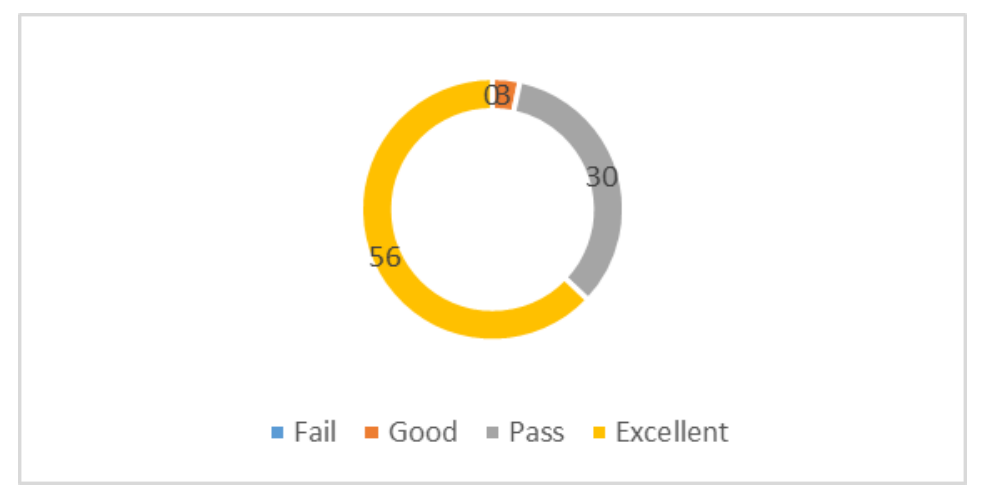

Figure 2 Participants' English Score In Gaokao

In general, these participants' English skills are good according to their English score in Gaokao (College Entrance Examination in China). The full mark of the English test in Gaokao is 150. To get an overview of participants' English level, the author classified their English score according to the following principles. Students' grades that are less than or equal to 90 are marked as "fail"; students" grades that are among 91 to 105 are marked as "pass"; students' grades that are among 106 to 120 are marked as "good"; students' grades that are equal or greater than 121 are marked as “excellent". Figure 2 shows the percentage of participants' score. It's clear that almost all of these participants' English level is at least "good". In addition, more than half of these participants' English level is "excellent".

\section{Research Methods}

This study employed both quantitative and qualitative research methods. Questionnaire is a common quantitative method that is usually adopted in student engagement researches. Thus, this study chose questionnaire to do the quantitative research. In regard to qualitative research method, interview was adopted to investigate supplementary information of students' engagement.

As it is mentioned before, Guo (2018) designed the College Student Agentic Engagement in English Scale for Chinese college students. There are 14 items in this scale. Most of them are classroom-based. This scale has four dimensions that are "self-study", "helping teachers with teaching', "cooperation with teachers" and "helping classmates with learning English". The reliability of the whole scale reaches over 0.900, all dimensions have good internal consistency, and the homogeneity of all the items is relatively high. Thus, this study chose Guo's scale as a basic model of the questionnaire used in this study.

The author changed questions in Guo's scale into questions relating to online learning. Besides, one question in Guo's scale is that "I don't study English hard" which is hard for student to rate. So, the author changed this question 
into "I always play on the phone while I am doing online listening tasks." Then the author set two reverse questions to check whether students fill in the questionnaire carefully or not. In order to be users-friendly, questionnaire used in this study was written in Chinese. This questionnaire mainly includes 5 parts. The first part is the basic information of respondents (gender, major, English score in Gaokao). The other four parts are the four dimensions that are "self-study", "providing teachers with suggestions", "cooperation with teachers" and "helping classmates learn English". There are 16 questions in total. The questionnaire asked the participants to rate on a 5-point scale ( $1=$ Strongly disagree, 2=Disagree, $3=$ Neutral, 4=Agree, 5=Strongly agree).

Reliability is an important indicator of the quality of a questionnaire. The Cronbach $\alpha$ coefficient values of each factor and total amount of this questionnaire are shown in Table 1. As it can be seen in Table 1, the coefficient of each dimension reaches 0.7 above which is an acceptable level. The results of the internal consistency test showed that the total reliability of this questionnaire is 0.892 , which suggests that the questionnaire used in this research is a reliable measuring tool.

TABLE 1.

THE RELIABILITY ANALYSIS RESULTS OF THE QUESTIONNAIRE

\begin{tabular}{cccccc}
\hline Name & Self-study & $\begin{array}{c}\text { Providing teachers } \\
\text { with suggestions }\end{array}$ & $\begin{array}{c}\text { Cooperation } \\
\text { with teachers }\end{array}$ & $\begin{array}{c}\text { Helping } \\
\text { classmates learn } \\
\text { English }\end{array}$ & $\begin{array}{c}\text { Total } \\
\text { questionnaire }\end{array}$ \\
\hline $\begin{array}{c}\text { Number of Item } \\
\text { Cronbach } \alpha\end{array}$ & 6 & 3 & 5 & 3 & 16 \\
\hline
\end{tabular}

To learn more about students' engagement in online English course, the author randomly chose two freshmen and two sophomores to do face-to-face interview. According to Reeve and Tseng (2011), agentic engagement is influenced by the other three kinds of engagement. Thus, the focuses of the interview are mainly about students' behavioral engagement, emotional engagement and cognitive engagement in online listening courses.

According to the definition of each kind of engagement, the author designed four questions for each kind of engagement. Questions concerning behavioral engagement mainly focused on students' attention, effort, and persistence in online listening tasks. For example, one of these questions was that "Did you always finish online listening tasks on time", which aimed to investigate students' persistence. Questions about emotional engagement mainly focused on students' interest, self-confidence and their views on the value of online listening tasks. For example, the author asked that "What do you think of this online listening course", in order to learn about students' views towards this online course. In regard to cognitive engagement, related questions mainly focused on students' usage of metacognitive strategy and cognitive strategy. For example, one of these questions was that "Did you plan for your listening tasks". By asking this question, the author aims to learn about the process of completing the online tasks.

\section{REsUlts}

\section{A. Results of the Questionnaire}

A total of 93 paper questionnaires were sent. Finally, after rejecting invalid questionnaire, the author got 89 valid questionnaires. Then the author used SPSS 22.0 to analyze the data. Table 2 below shows the mean of each dimension in detail.

The total agentic engagement value of these participants was in a moderate level $(\mathrm{MD}=3.55)$. In regard to the agentic engagement of each grade, there was a decline trend from freshman to sophomore. In terms of each dimension, freshman's agentic engagement was a little bit higher than sophomore. It can be seen that the mean of the dimension "Providing teachers with suggestions" was the lowest $(\mathrm{MD}=2.59)$ and "Cooperation with teachers" was the highest $(\mathrm{MD}=3.94)$ among the four, which suggests that these students always cooperated with their English teachers, but they seldom provided teachers with suggestions. The mean of "self-study" (MD=3.78) was higher than "helping classmates learn English" $(\mathrm{MD}=3.51)$. Thus, compared with "helping classmates learn English", these students did more in "self-study".

TABLE 2.

MEAN OF EACH DIMENSION

\begin{tabular}{cccccc}
\hline Grade & Self-study & $\begin{array}{c}\text { Providing teachers } \\
\text { with suggestions }\end{array}$ & $\begin{array}{c}\text { Cooperation } \\
\text { with teachers }\end{array}$ & $\begin{array}{c}\text { Helping } \\
\text { classmates learn } \\
\text { English }\end{array}$ & Total \\
\hline Freshman & 3.82 & 2.67 & 3.97 & 3.60 & 3.60 \\
Sophomore & 3.74 & 2.50 & 3.90 & 3.43 & 3.49 \\
Mean & 3.78 & 2.59 & 3.94 & 3.51 & 3.55 \\
\hline
\end{tabular}

\section{B. Results of Students' Weekly Online Test Score}

The author calculated the average score of 13 weekly tests whose full mark is 100 . The average score of freshman and sophomore are 98.78 and 98.95. The results indicate that these participants did extremely well in their weekly online tests. In addition, Pearson correlation analysis shows that there is no significant correlation between students' 
agentic engagement and their average score of weekly online listening courses ( $\mathrm{r}=-0.173, \mathrm{p}>0.01)$. Thus, students' high score of online listening tasks doesn't mean their highly agentic engagement in online listening tasks. Reasons behind this phenomenon need to be further studied.

\section{Results of Interview}

The author interviewed four of these participants. The four students all actively expressed their views towards this online listening course. After synthesized the interview data, the author found the following results.

First, the four students' behavioral engagement was nearly the same. All of the four interviewees finished their online listening tasks on time. If they don't know a word, they will look it up in a dictionary. Besides, they also used extra online listening materials given by teachers or found by themselves to develop their listening skills. Only one freshman said that she didn't play with her phone while she was finishing her online tasks, for she believed that listening tasks need her to keep the brain occupied. The other three students admitted that sometimes they played with their phones when the listening materials were too long or too boring.

Secondly, the four students' emotional engagement was different. An interesting finding was that the two freshmen thought highly of the materials provided by this online listening platform, while the two sophomores thought that these listening materials were useless for them. One sophomore said that, "I think these listening materials weren't designed for our college students. They were too easy for us. Doing online listening tasks was very boring. I don't like this online listening course." As for their self-confidence in listening proficiency, the four students were not so confident. However, they all admitted that they got nearly full marks in their online listening tests for they were too easy for them. Two sophomores mentioned that most of their classmates could easily found answers of online tests on the internet, which helps to explain the high marks of their online listening tests.

Lastly, the four students' cognitive engagement was nearly the same. It seems that the four students hardly used metacognitive strategies. The four participants admitted that they didn't set goals or plan for their online listening tasks. Besides, they didn't do self-evaluation or change their habits of doing online listening tasks when facing different kinds of listening materials. In term of their usage of cognitive strategy, they all mentioned that they always summed up their listening experience and applied those experiences to promote their listening comprehension. Such as note-taking, prediction, etc. One student mentioned that teachers didn't give them any help in listening strategy training. All the four students thought listening strategy training was important.

\section{DISCUSSION}

Question 1: What's the current situation of students' agentic engagement in online learning?

After analyzing the results, the author got the following findings:

1) In terms of students' agentic engagement, there was a decline trend from freshmen to sophomores.

The total agentic engagement value of these participants was in a moderate level, which suggested that teachers could do more to improve students' agentic engagement. In regard to each agentic engagement dimension, freshmen's agentic engagement was higher than sophomores'. This phenomenon may be caused by various factors. One of these factors was the online course design, which was proved to be an important factor that may influence students' online learning engagement (Pollock \& Wilson, 2002). With the same e-learning platform, the two freshmen said that materials provided in this e-learning platform were interesting, while the two sophomores said it was boring and too easy. This phenomenon indicated that the materials provided in this learning platform didn't match students' English level, which strongly influenced students' agentic engagement. Thus, the materials provided for each grade need to be designed and selected so as to meet the needs of different students.

In addition, learners' emotional engagement also influenced their agentic engagement (Reeve \& Tseng, 2011). According to the results of the interview, the two freshmen hold totally different views on the value of this online listening course. The two freshmen said that materials provided in this e-learning platform were interesting and good for their listening skills development. However, the two sophomores said that this online listening course can't help them develop their listening skills, but waste their time. Low quality or mismatching listening material lead to these four interviewees' low emotional engagement in this online listening course, but these interviewees had similar behavioral engagement and cognitive engagement. With different emotional engagement, different students showed different agentic engagement. This phenomenon also indicated that this e-learning platform can't meet different students' need. Thus, a more effective e-learning platform is needed.

2) There was a lack of teacher-student interaction and student-student interaction.

The results of the questionnaire and interview suggested that students always cooperated with their English teachers, but they seldom provided teachers with constructive suggestions. The two sophomores both mentioned that they didn't communicate with their teachers, but they submitted their online assignments on time. What's more, all the listening strategies these students used were summed up by themselves, rather than provided by their teachers. There was no teacher intervention. Apart from that, students did more in self-study than in helping their classmates learning English, which was in accordance with Dumford and Miller (2018)'s research that found students of different grades showed less collaborative learning activities in online learning background.

Results above suggested that there was a lack of teacher-student interaction and student-student interaction in this 
e-learning process. It was already proved that students had lower quality of interactions with greater numbers of online courses (Dumford \& Miller, 2018). Although this e-learning platform already had a teacher-student and student-student interaction application by which teachers and students can send message to each other. However, teachers and students hardly used them, which indicated that the interaction application existed in name only. Students just do self-study passively without teachers' or their classmates' feedback. Compared with face-to-face setting, students may feel more isolation from their teachers which may influence their engagement (Wijekumar et al., 2006). Besides, without interaction with their classmates may increase their feeling of isolation. Just as one interviewee said that it seems that they had self-study listening course without any guidance from their teachers, but they had pay for this course. Moreover, these online listening materials were boring and don't match their English level, so many classmates around her don't like this online listening course. Thus, apart from the online course design, teacher's intervention and teacher-student interaction and student-student interaction also influence students' agentic engagement.

It is clear that online learning course doesn't mean totally let student do autonomous learning. Teachers actually played greater role of class management in online learning where students are supposed to have higher degree of learning autonomy (Huang, 2019). Besides, Huang (2019) found that teachers are still needed to assist students with deeper level of cognitive processes, although online courses can replace teachers to deliver knowledge and rich materials. At last, not all the teaching activities could adapt to the online format, which may cause lose interaction between classmates and/ or instructors (Shuey, 2002). However, student's agentic engagement includes their interaction between classmates and teachers. Therefore, the e-learning format may influence students' agentic engagement to a certain extent. In conclusion, it is of great importance to further explore students' agentic engagement in online learning background, and to deeply investigate the influence of teacher intervention, teacher-student interaction, student-student interaction on students' agentic engagement.

Question 2: Does student's agentic engagement corelate with their online test scores?

The results suggested that student's agentic engagement didn't corelate with their online test scores. Students could easily get a high mark in online listening tests, while their agentic engagement was different. According to the results of questionnaire and interview, the author found the following possible reasons. 1) Online tests were too simple for these students. 2) Students could easily find answers on the internet and they copied these answers to get a high score. Results above suggested that there is a lack of effective online assessment method. Thus, the author got the following findings.

Firstly, the reliability of these online tests required to be measured. Traditionally in higher education, summative assessment is the most common used type of assessment, which was also used in this online listening course. Summative assessment usually comprises a final grading - the average grade for all the activities or exams conducted during the course (Guerrero-Roldán \& Noguera, 2018). According to the interview, one of the biggest problems was that the tests don't match the users' English level. These online listening tests were too easy for these students, which may lead to the result that the teachers couldn't get students' real learning outcomes according to their online test scores. Students could easily get a high mark in these test score, but they still didn't have any confidence in their listening skills. This kind of invalid test also caused another big problem that students may perceive it unfair when teachers took these online test grades as students final course scores. One interviewee said, "I don't like this kind of assessment. It's unfair, for I finished these online tests totally by myself but got a lower score than students who cheat." This phenomenon was in accordance with Dermo (2009)'s argument that students may perceive it as unfair when online test score provided by grades or standard comments is translated into information on performance. Therefore, a multi-dimensional assessment system is necessary.

In addition, cheating was also a big problem that reduced the benefits of internet-based testing and influence students' agentic engagement. In large class sizes, it is hard for teachers to give students' timely and personalized feedback. In these cases, online tests are becoming a suitable solution for providing students with feedback regardless of class size (Hepplestone, Holden, Irwin, Parkin, \& Thorpe, 2011). However, as one of the interviewees mentioned that many students could easily found the answers of the online tests, and many of her classmates directly cheated to get a full mark. Because of without the human proctor's supervision, problems with looking up solutions on the internet are inherent to online assessment (Diedenhofen \& Musch, 2017). In addition, listening tests for each grade on this e-learning platform were fixed, which lead to the accurate answers for each test published on the internet. All these factors may result in students' cheating. Thus, there was a particular need of students' highly self-control in online test. Besides, the problem of how to avoid students' cheating should be solved.

Suggestions

Given those findings above, the author found the following suggestions:

Firstly, an adaptive e-learning system may solve both the problem of students' cheating and individual difference. The e-learning system used in this study didn't offer the opportunity to adapt the users' need. Students were forced to proceed according to fixed course arrangements. Adaptive e-learning system is designed to provide efficient and formal learning via supporting different learning paths and materials to fit learners' diverse needs and backgrounds (Bra, Brusilovsky, \& Houben, 1999). An adaptive e-learning system could meet different students need according to their English level. Besides, different students may have different listening materials because of their different feedback with an adaptive e-learning system. Then, there will be no fixed test or course on an adaptive e-learning platform, which means it is hard for students to cheat. 
Secondly, to increase teacher-student and student-student online interaction, the feedback loop between teacher and student must be adapted in online learning courses (Wijekumar et al., 2006). Technologically, effective technical support, such as user-friendly teacher-student interaction and student-student interaction application is necessary. The failed design of e-learning platform can lead to a negative impact on students' overall perception of the course (Pollock \& Wilson, 2002). Thus, user-friendly technology support is crucial. Pedagogically, blended learning, the combination of traditional face-to-face teaching with multimedia assisted instruction, could be applied to listening course. Blended combines the advantages of both face-to-face learning and online learning at different levels of education and it has been considered to be an important alternative instruction mode (Huang, 2019). With blended learning mode, there will be more opportunity for teacher-student and student-student interaction, which is good to reduce student's feeling of isolation so as to improve students' engagement.

Lastly, teachers could adopt formative assessment to this online course. Teachers in this study got students' feedback only by these online tests, because there was no face-to-face interaction between teachers and students. However, it is problematic to overreliance on the summative feedback from graded quizzes and exams which might limit the formative feedback given to students during the learning process (Dumford \& Miller, 2018). Formative assessment which is always combined with summative assessment could be used in this online listening course. There is an iterative process in formative assessment. In the iterative process, students receive information about their learning process and learn from it. Mainly, formative assessment based on teachers' feedback, and it can be more productive if it is based on self-assessment and peer-assessment (Gikandi, Morrow, \& Davis, 2011).

\section{CONCLUSION}

According to this research, students' agentic engagement in e-learning course was in a moderate level and there was a decline trend from freshman to sophomore. Besides, there was a lack of teacher-student interaction and student-student interaction in this online learning course. As for students' online tests, student's agentic engagement didn't correlate with their online test scores. With those findings, the author found that there was room for improvement both in course design and this e-learning platform. In terms of course design, the current online course can't meet different students' need, and there was a lack of teacher-student and student-student interaction. In regard to the assessment system, this online course totally relied on summative assessment which is problematic. According to these problems, the author found some possible suggestions for teachers, such as self-adaptive learning platform, blended learning mode and multi-dimensional assessment which could help to solve these problems and improve students' agentic engagement. Due to the limitation of time and resources, the author did this study in a small sample size. However, it is hoped that this study could provide reference for future online agentic engagement research.

\section{REFERENCES}

[1] Astin, A. (1999). Student involvement: A developmental theory for higher education (Reprinted from Journal of College Student Development, July, 1984). Journal of College Student Development (No.5), 518-529.

[2] Bandura, A. (2018). Toward a Psychology of Human Agency: Pathways and Reflections. Perspectives on Psychological Science (PERSPECT PSYCHOL SCI), 13(2), 130-136.

[3] Beachboard, M. R., Beachboard, J. C., Li, W., \& Adkison, S. R. (2011). Cohorts and Relatedness: Self-Determination Theory as an Explanation of How Learning Communities Affect Educational Outcomes. Research in Higher Education, 52(8), 853-874.

[4] Blake, R. J. (2009). The Use of Technology for Second Language Distance Learning. Modern Language Journal, 93(s1), 822-835.

[5] Bra, P. D., Brusilovsky, P., \& Houben, G.-J. (1999). Adaptive hypermedia: from systems to framework. ACM Computing Surveys, 31(4es), 1-6.

[6] Caraway, K., Tucker, C. M., Reinke, W. M., \& Hall, C. (2003). Self-efficacy, goal orientation, and fear of failure as predictors of school engagement in high school students. Psychology in the Schools, 40(4), 417-427.

[7] Christenson, S. L., Reschly, A. L., \& Wylie, C. (Eds.). (2012). The handbook of research on student engagement. New York: NY: Springer Science.

[8] Dermo, J. (2009). E-assessment and the student learning experience: A survey of student perceptions of e-assessment. British Journal of Educational Technology, 40, 203-214.

[9] Diedenhofen, B., \& Musch, J. (2017). PageFocus: Using paradata to detect and prevent cheating on online achievement tests. Behavior Research Methods, Instruments and Computers, 49(4), 1444-1459.

[10] Dumford, A. D., \& Miller, A. L. (2018). Online learning in higher education: exploring advantages and disadvantages for engagement. Journal of Computing in Higher Education, 30(3), 452-465.

[11] Fitzpatrick, J., O'Grady, E., \& O'Reilly, J. (2018). Promoting student agentic engagement through curriculum: exploring the Negotiated Integrated Curriculum initiative. Irish Educational Studies, 37(4), 453-473.

[12] Fletcher, A. K. (2016). Exceeding expectations: scaffolding agentic engagement through assessment as learning. Educational Research, 58(4), 400-419.

[13] Fredricks, J. A., Blumenfeld, P. C., \& Paris, A. H. (2004). School engagement: Potential of the concept, state of the evidence(Review). Review of Educational Research, 74(1), 59-109.

[14] Gikandi, J. W., Morrow, D., \& Davis, N. E. (2011). Online formative assessment in higher education: A review of the literature Computers \& Education, 57(4), 2333-2351.

[15] Guerrero-Roldán, A.-E., \& Noguera, I. (2018). A model for aligning assessment with competences and learning activities in 
online courses. Internet \& Higher Education, 38, 36-46.

[16] Guo, J. D. (2018). Effect of EFL Writing Self-concept and Self-efficacy on Writing Performance: Mediating Role of Writing. Foreign Language Research(02), 69-74.

[17] Guo, J. D., \& Li, Y. (2018). The Development and Validation of Scale of Agentic Engagement with Foreign Language Learning. Foreign Language Education, 39(05), 66-69.

[18] Guo, J. D., \& Liu, L. (2016). Devotion to FL Learning: Connotation, Structure and Research Perspective. Journal of Jiangxi Normal University (Philosophy and Social Sciences Edition), 49(06), 181-185.

[19] Han, X. L. (2014). Analysis on Influencing Factors of College Student Engagement Based on NSSE-CHINA. (Master), Nanjing University of Posts and Telecommunications, Nanjing.

[20] Henrie, C. R., Halverson, L. R., \& Graham, C. R. (2015). Measuring student engagement in technology-mediated learning: A review. Computers \& Education, 90, 36-53.

[21] Hepplestone, S., Holden, G., Irwin, B., Parkin, H. J., \& Thorpe, L. (2011). Using technology to encourage student engagement with feedback: A literature review. Research in Learning Technology, 19(2), 117-127.

[22] Hockly, N. (2015). Developments in online language learning. Elt Journal(No.3), 308-313.

[23] Huang, Q. (2019). Comparing teacher's roles of f2f learning and online learning in a blended english course. Computer Assisted Language Learning, 32(3), 190-209.

[24] Jacob, S., \& Radhai, S. (2016). Trends in ICT e-learning: Challenges and expectations. International Journal of Innovative Research \& Development, 5, 196-201.

[25] Mameli, C., \& Passini, S. (2019). Development and Validation of an Enlarged Version of the Student Agentic Engagement Scale. Journal of Psychoeducational Assessment(No.4), 450-463.

[26] Manzuoli, C. H., Pineda-Báez, C., \& Sánchez, A. D. V. (2019). School Engagement for Avoiding Dropout in Middle School Education. International Education Studies(No.5), 35-48.

[27] Maralani, F. M., Shalbaf, A., \& Lavasani, M. G. (2018). Agentic Engagement and Test Anxiety: The Mediatory Role of the Basic Psychological Needs. SAGE OPEN(No.2), 1-7.

[28] Pineda-Báez, C., Hennig Manzuoli, C., \& Vargas Sánchez, A. (2019). Supporting student cognitive and agentic engagement: Students' voices. International Journal of Educational Research, 96, 81-90.

[29] Pollock, P. H., \& Wilson, B. M. (2002). Evaluating the Impact of Internet Teaching: Preliminary Evidence from American National Government Classes. Political Science Politics, 35(03), 561-566.

[30] Reeve, J. (2013). How Students Create Motivationally Supportive Learning Environments for Themselves: The Concept of Agentic Engagement. Journal of Educational Psychology, 105(3), 579-595.

[31] Reeve, J., \& Tseng, C.-M. (2011). Agency as a fourth aspect of students' engagement during learning activities. Contemporary Educational Psychology, 36(4), 257-267.

[32] Restauri, S. L., King, F. L., \& Nelson, J. G. (2001). Assessment of Students' Ratings for Two Methodologies of Teaching via Distance Learning: An Evaluative Approach Based on Accreditation. ERIC document 460-148, reports-research (143).

[33] Shuey, S. (2002). Assessing online learning in higher education. Journal of Instruction Delivery Systems, 16, 13-18.

[34] Su, Q. (2019). An SEM Study of College Students' Engagement in English Learning. Foreign Language Learning Theory and Practice $(01), 83-88+47$.

[35] Wang, W., Guo, L., He, L., \& Wu, Y. J. (2019). Effects of social-interactive engagement on the dropout ratio in online learning: insights from MOOC. Behaviour \& Information Technology (No.6), 621-636.

[36] Wijekumar, K., Ferguson, L., \& Wagoner, D. (2006). Problems with Assessment Validity and Reliability in Web-Based Distance Learning Environments and Solutions. Journal of Educational Multimedia \& Hypermedia, 15(June), 199-215.

[37] Yang, L. J., \& Han, X. L. (2014). A Study on the Structure of College Students' Learning Engagement: Based on NSSE-CHINA. Fudan Education Forum, 12(03), 83-90.

Yanxiu Dong was born in Hebei Province, China in 1992. She will receive her Master's Degree in TESOL from Beijing International Studies University, China in 2020. Her research interests include linguistics, critical discourse analysis and English teaching.

Suli Liu is currently Associate Professor in Beijing International Studies University. She earned a Master's degree in TESOL in Dalian Maritime University. She has authored 2 and co-authored 6 books and textbooks in Language teaching. Also she has published more than 20 research papers on Language teaching and Literature. Her main research interests are applied Linguistics and Literature. 